OPEN ACCESS

Edited by:

Samuel Abiven,

Universität Zürich, Switzerland

Reviewed by:

Melanie Bläsing,

Universität Bonn, Germany

Sasha Wagner,

Northeastern University, United States

*Correspondence:

Andrew R. Zimmerman

azimmer@ufl.edu

Specialty section:

This article was submitted to

Biogeoscience,

a section of the journal

Frontiers in Earth Science

Received: 23 January 2018 Accepted: 09 April 2018

Published: 24 April 2018

Citation:

Bostick KW, Zimmerman AR, Wozniak AS, Mitra S and Hatcher PG (2018) Production and Composition of

Pyrogenic Dissolved Organic Matter

From a Logical Series of Laboratory-Generated Chars.

Front. Earth Sci. 6:43

doi: 10.3389/feart.2018.00043

\section{Production and Composition of Pyrogenic Dissolved Organic Matter From a Logical Series of Laboratory-Generated Chars}

\author{
Kyle W. Bostick ${ }^{1}$, Andrew R. Zimmerman ${ }^{1 *}$, Andrew. S. Wozniak ${ }^{2}$, Siddhartha Mitra ${ }^{3}$ and \\ Patrick G. Hatcher ${ }^{4}$ \\ ${ }^{1}$ Department of Geological Sciences, University of Florida, Gainesville, FL, United States, ${ }^{2}$ School of Marine Science and \\ Policy, College of Earth, Ocean, and Environment, University of Delaware, Newark, DE, United States, ${ }^{3}$ Department of \\ Geological Sciences, East Carolina University, Greenville, NC, United States, ${ }^{4}$ Department of Chemistry and Biochemistry, \\ Old Dominion University, Norfolk, VA, United States
}

Though pyrogenic carbon (pyC) has been assumed to be predominantly stable, degradation and transfers of pyC between various pools have been found to influence its cycling and longevity in the environment. Dissolution via leaching may be the main control on loss processes such as microbial or abiotic oxidation, mineral sorption, or export to aquatic systems. Yet, little is known about the controls on pyrogenic dissolved organic matter (pyDOM) generation or composition. Here, the yield and composition of pyDOM generated through batch leaching of a thermal series of oak and grass biochars, as well as several non-pyrogenic reference materials, was compared to that of their parent solids. Over 17 daily leaching cycles, biochars made from oak at $250-650^{\circ} \mathrm{C}$ released decreasing amounts of $\mathrm{C}$ on both a weight (16.9-0.3\%, respectively) and C yield basis (7.4-0.2\% C, respectively). Aryl-C represented an estimated 32-82\% of $\mathrm{C}$ in the parent solids (identified by ${ }^{13} \mathrm{C}-\mathrm{NMR}$ ), but only $7-38 \%$ in the leachates (identified by ${ }^{1} \mathrm{H}-\mathrm{NMR}$ ), though both increased with pyrolysis temperature. PyC, often operationally defined as condensed aromatic carbon (ConAC), was quantified using the benzenepolycarboxylic acid (BPCA) method. Tri- and tetra-carboxylated BPCAs were formed from non-pyrogenic reference materials, thus, only penta- and hexa-carboxylated BPCAs were used to derive a BPCA-C to ConAC conversion factor of 7.04. ConAC made up $24-57 \%$ of the pyrogenic solid $\mathrm{C}$ (excluding the $250^{\circ} \mathrm{C}$ biochar), but only about 9-23\% of their respective leachates' DOC, though both proportions generally increased with pyrolysis temperature. Weighted BPCA compound distributions, or the BPCA Aromatic Condensation (BACon) Index, indicate that ConAC cluster size increased in pyrogenic solids but not in leachates. Additional evidence presented suggests that both aromatic cluster size and $\mathrm{O}$-containing functional group contents in the pyrogenic solid control pyC solubility. Overall, pyDOM was found to be compositionally dissimilar from its parent chars and contained a complex mixture of organic compound groups. Thus, it is expected that estimates of dissolved pyC production and export, made only by detection of ConAC, are too low by factors of $4-11$.

Keywords: dissolved organic matter (DOM), pyrogenic carbon, biochar, charcoal, benzenepolycarboxylic acid (BPCA), leaching, fire, black carbon 


\section{INTRODUCTION}

Pyrogenic organic matter (pyOM), is a physically- and chemically-diverse suite of carbonaceous products generated during the incomplete combustion of biomass (e.g., charcoal and soot). Given that climate change is likely to increase the frequency and intensity of wildfires (Bowman et al., 2009) and the growing interest in the application of pyrolyzed waste agricultural biomass (biochar) to agricultural soils (Spokas et al., 2012), pyOM may become more abundant in the bioand geosphere in the future. Therefore, a more complete understanding of the global cycling of pyrogenic carbon (pyC), often referred to as "black carbon" (BC), is needed. While we are beginning to better quantify the global production of pyC from wildfires and anthropogenic burning, we have a poor understanding of its mobility and geochemical fate in the environment.

PyOM has been generally characterized as a recalcitrant form of organic matter. However, using today's pyC production rate via natural and anthropogenic biomass burning (50-300 Tg yr1, Kuhlbusch and Crutzen, 1996; Forbes et al., 2006; Bird et al., 2015), soil C would be $25-125 \%$ pyC after just 7,000 years (Masiello, 2004). A current estimate of soil pyC (in the uppermost $2 \mathrm{~m}$ ) is $\sim 200,000 \mathrm{Tg}$ (Reisser et al., 2016). Since soil C is only $\sim 10 \%$ pyC, on average (e.g., Bird et al., 1999; Hammes et al., 2007; Cusack et al., 2012), significant pyC losses must occur.

PyOM releases pyrogenic dissolved organic carbon (pyDOC) into aqueous solution via dissolution or "leaching." For example, one leaching experiment recorded losses of about $0.3 \%$ of the initial $\mathrm{C}$ in fresh and aged chars over a period of only $6 \mathrm{~h}$ (Abiven et al., 2011). Another laboratory leaching study examining the effects of repeated leaching estimated that up to $3.7 \%$ of biochar $\mathrm{C}$ could be lost to dissolution annually in sandy soils (Mukherjee and Zimmerman, 2013; Zimmerman and Gao, 2013). It is likely, though not yet adequately shown, that both abiotic (e.g., chemical oxidation and photooxidation) and biotic degradation (microbial enzymatic attack) enhances the production of watersoluble constituents of pyOM (Abiven et al., 2011; Mukherjee and Zimmerman, 2013) and even more pyDOC may be released than these studies suggest. Furthermore, the effects of bulk DOC on pyC solubility has been investigated to a minor extent (Wagner et al., 2017).

The production of pyOM converts labile $\mathrm{C}$ (biomass) into recalcitrant forms that can be stored in the geosphere, making it an important component in the global $\mathrm{C}$ cycle with implications for atmospheric $\mathrm{CO}_{2}$ concentrations, and thus, climate variations through time. An improved understanding of the composition, mobility, and stability of pyrogenic dissolved organic matter (pyDOM) in the environment is thus essential.

\section{Pyrogenic Organic Matter Chemistry}

The chemical composition of pyOM solids has been recognized to be highly complex (Schneider et al., 2010, 2013; Cao et al., 2012), though it can be generalized as biphasic, consisting of both a condensed aromatic portion and a more aliphatic, non-condensed portion (Hockaday et al., 2007). Because the condensed aromatic property of pyOM has often been used to quantify pyC, we coin the term "ConAC" (condensed aromatic carbon) to refer only to this portion rather than the chemically ambiguous term "black carbon." In biochars and charcoals, the proportion of ConAC varies with biomass type and charring conditions, but it generally increases with the temperature and duration of pyrolysis (Schneider et al., 2010, 2013; McBeath et al., 2011; Wolf et al., 2013).

Variations in parent solid composition are assumed to dictate the leachability and production of pyDOM from biochars and charcoals. Experiments have shown that chars produced at lower temperatures (e.g., $<400^{\circ} \mathrm{C}$ ) contain more readily soluble constituents than those produced at higher temperature (e.g., $>400^{\circ} \mathrm{C}$ ) (Mukherjee and Zimmerman, 2013). Feedstock has also been shown to affect pyDOM production; in an aqueous leaching study, Wagner et al. (2017) found that rice straw chars produce about 5.5 times as much pyDOC as chestnut wood chars relative to their $\mathrm{C}$ content. Environmental exposure may also affect the abundance and composition of leached pyDOM. For example, $\sim 50$ times more ConAC was released from aged chestnut wood chars than from freshly made chars (Abiven et al., 2011). Similar results were observed by Roebuck et al. (2017). Using Fourier-transform ion cyclotron resonance mass spectrometry (FTICR-MS), Hockaday et al. (2006) estimated that the water-soluble portion of soil charcoal contained 1,200 unique formulas corresponding to condensed aromatic ring structures that constituted about $65 \%$ of the total peaks observed. In marine DOM, these condensed aromatic compounds consist of only seven fused aromatic rings, on average, and are substituted with oxygen-containing functional groups (e.g., carboxyl, hydroxyl, and aliphatic, Koch and Dittmar, 2006). A significant portion of the oxygenated polycyclic aromatic hydrocarbons in marine DOM are thought to be pyrogenic (Hockaday et al., 2006), though this is based only on the similarities in structure derived from $\mathrm{O} / \mathrm{C}$ and $\mathrm{H} / \mathrm{C}$ ratios. In addition to condensed aromatic hydrocarbons, pyDOM must also contain aliphatic and noncondensed aromatic OM, though this is seldom investigated in detail or even acknowledged in the context of the global pyC cycle. Thus, improvements are needed in our ability to account for all components of pyDOM in the environment and distinguish it from non-pyrogenic DOM.

\section{Pyrogenic Carbon Quantification Method}

Quantification of pyC in soils, sediments, and DOM has been performed using a variety of methods that rely on the general properties of pyrogenic materials including morphology, light absorption, thermochemical stability, and chemical composition (Hammes et al., 2007). Of these, the method most commonly used for pyDOC analysis involves the acid-mediated oxidation of ConAC constituents of pyDOM into smaller, quantifiable molecular markers (i.e., benzenepolycarboxylic acids or BPCAs). These BPCA molecules consist of a central benzene ring with two to six carboxylic acid functional groups. Historically, only compounds that can produce three to six carboxyl substitutions are quantified as ConAC. However, because not all ConAC is converted to BPCA carbon (BPCA-C), total ConAC is calculated via a conversion factor, and is assumed to be exclusively pyrogenic. The method also provides structural information 
about ConAC in the form of BPCA molecular distribution. Production of BPCAs with higher levels of carboxylation (e.g., benzenepentacarboxylic acids and benzenehexacarboxylic acids, B5CA and B6CA) are thought to indicate greater aromatic condensation or aromatic "cluster size" (Ziolkowski and Druffel, 2009, 2010; Schneider et al., 2010, 2011).

Using this BPCA method, substantial quantities of "pyDOC" (reported as dissolved black carbon, DBC) have been reported in aquatic systems and rivers (Dittmar et al., 2012b; Jaffé et al., 2013), subtropical wetlands (Ding et al., 2014), intertidal systems (Dittmar et al., 2012b), glacial melt systems (Nakane et al., 2017), and open marine environments (Ziolkowski et al., 2011). Jaffé et al. (2013) calculated that "pyDOC" comprises from 0.1 to $17.5 \%$ of global riverine DOC. Despite this, total DOC and "pyDOC" concentrations were highly correlated in this and several other BPCA-based studies (e.g., Dittmar et al., 2012b; Ding et al., 2013, 2014) suggesting that pyDOC represents a relatively constant proportion of riverine DOC globally $(\sim 10 \%$ pyDOC/DOC). This conclusion is potentially problematic since one would expect this ratio to vary with regional climate, burning regimes, and soil characteristics.

While the BPCA method has been adapted and improved recently to reduce artifacts Brodowski et al. (2005), some caveats and assumptions still must be considered. This method does not target aliphatic or other non-condensed compounds in pyDOM, as they likely do not form BPCA compounds upon nitric acid oxidation. Aliphatic and O-containing components are likely to be more soluble than the condensed aromatic fraction, thus may represent a large portion of pyDOM, as directly identified using FTICR-MS (Podgorski et al., 2012; Ward et al., 2014). It is also unclear if the BPCA method quantifies pyC, exclusively. The method may result in some non-pyrogenic DOC (such as humic substances) being identified as pyrogenic (Kappenberg et al., 2016; Zimmerman and Mitra, 2017). Aside from the potential for false positives, other difficulties arise from the choice of conversion factor and methods used to convert measured BPCA-C of a sample to the amount of ConAC. These range from 2.3 to 4.4 ((Glaser et al., 1998; Ziolkowski and Druffel, 2009), respectively) using gas chromatography method (GC) which requires a derivatization step, and about 3 based on FTICR-MS and HPLC (Dittmar, 2008). Another conversion factor would be needed if not all pyC were condensed aromatics. Clearly, the abilities and limitations of the BPCA method to quantify pyC, particularly in dissolved form, must be further explored.

While many natural DOM samples have been analyzed using the BPCA method, to our knowledge, only two studies examined well-characterized pyrogenic solid leachates (Abiven et al., 2011; Wagner et al., 2017). Here, pyDOM was extracted using batch leaching experiments on a series of biochars as well as several non-pyrogenic reference materials. Specific objectives of this study were to: (1) determine how pyDOC and BPCA production vary with pyrogenic solid type (range of pyrolysis temperatures and feedstock types) and over the course of leaching, and (2) examine how pyDOM composition relates to its parent pyrogenic solid type (using the BPCA technique as well as ${ }^{13} \mathrm{C}$ - and ${ }^{1} \mathrm{H}$ NMR analysis).
We hypothesize that pyDOC production, i.e., solubility, will be controlled by both abundance of $\mathrm{O}$-containing functional groups and ConAC cluster size (as evidenced by ${ }^{13} \mathrm{C}-\mathrm{NMR}$ and ${ }^{1} \mathrm{H}-\mathrm{NMR}$ group, and BPCA molecular distributions, respectively). Further, we expect that the chemical composition of the produced pyDOM will be different from that of its parent solid phase, reflecting relative compound solubility instead of parent phase abundance. Specifically, we hypothesize that the biochar leachates should contain more O-containing function groups and less condensed aromatic content (or at least smaller aromatic clusters) than their respective solids. In testing these hypotheses, we hope to clarify the inferences that can be made using BPCA biomarkers in regards to natural DOM samples, as well as to improve our understanding of the mechanisms involved in pyC production and fate.

\section{METHODS AND MATERIALS}

\section{Materials \\ Parent Solids}

Biochars were produced from laurel oak wood (Quercus hemisphaerica) by combustion at $250^{\circ} \mathrm{C}$ in a furnace (Oak250 ) and by pyrolysis under flowing nitrogen gas (held at peak temperatures of 400,525 , and $650^{\circ} \mathrm{C}$ for $3 \mathrm{~h}$, hereby denoted as Oak-400, Oak-525, and Oak-650). Using the same pyrolysis technique, biochars were prepared from dwarf Fakahatchee grass sheaths (Tripsacum floridanum) at 400 and $650^{\circ} \mathrm{C}$ (i.e., Grass- 400 and Grass-650). Lastly, laurel oak wood was pyrolyzed at $650^{\circ} \mathrm{C}$ for $24 \mathrm{~h}$ (Oak-650-24h). Physiochemical data on these biochars have been reported previously (Zimmerman, 2010; Mukherjee et al., 2011). Non-pyrolyzed reference materials included the wood, the grass, and pyrogenic-free leaf-litter compost. A mortar, pestle, and sieve were used to achieve solid samples with a semi-uniform $0.25-2.0 \mathrm{~mm}$ particle size. Additional reference materials analyzed included pristine multiwall carbon nanotubes (750 nm diameter; from SinoNano Tech Corp.) and graphene oxide (from JCNANO) which were considered semi-pure forms of condensed aromatics.

\section{Experimental and Analytical Methods}

Approximately $1 \mathrm{~g}$ of each solid sample was added to $40 \mathrm{ml}$ of MilliQ Nanopure water $(18.1 \mathrm{M} \Omega$ ) in a $250 \mathrm{ml}$ glass flask (all glassware throughout the experiment was pre-cleaned via combustion at $500^{\circ} \mathrm{C}$ for $3 \mathrm{~h}$ ). These flasks were placed on a platform shaker and agitated at $120 \mathrm{rpm}$ in the dark. After $24 \mathrm{~h}$, the overlying supernatants were removed and stored in a refrigerator at $4^{\circ} \mathrm{C}$. The $40 \mathrm{ml}$ of water was replaced in each flask and they were returned to the shaker-table and agitated for another $24 \mathrm{~h}$ (day 2). Then, the $40 \mathrm{ml}$ supernatants of each sample were combined with the previous leachate. These day 1 - and 2- combined leachates were designated "Early" pyDOM leachates. This process was repeated, but with $100 \mathrm{ml}$ additions, for 13 more $24 \mathrm{~h}$ periods. On days 16 and 17, the corresponding $40 \mathrm{ml}$ supernatant were combined and designated "Late" pyDOM leachates.

All "Early" and "Late" leachates were pre-filtered through combusted $\left(450^{\circ} \mathrm{C}\right)$ Fisherbrand G2 glass fiber filters $(1.0 \mu \mathrm{m}$ 
particle retention), then vacuum-filtered using a $0.45 \mu \mathrm{m}$ mixed cellulose ester filter (Millipore). All filtrates were analyzed for DOC on a Shimadzu TOC-V $\mathrm{V}_{\mathrm{CSN}}$ after acidification to $\mathrm{pH} 2$ with trace metal grade hydrochloric acid and sparging for $2 \mathrm{~min}$ with $\mathrm{N}_{2}$ to remove dissolved inorganic C. Standard curves were generated using concentrations of potassium biphthalate solutions ranging from 0.4 to $40.0 \mathrm{mg} \mathrm{L}^{-1}\left(\mathrm{C}_{8} \mathrm{H}_{5} \mathrm{KO}_{4}\right.$; SigmaAldrich, >99.95\%).

\section{Solid Phase Extraction}

Prior to BPCA analyses, pyDOM leachates were concentrated using solid phase extraction (SPE), following Dittmar (2008) and Dittmar et al. (2008). Agilent PPL cartridges (3 ml, $100 \mathrm{mg}$ ) were rinsed with at least $10 \mathrm{ml} \mathrm{HPLC}$-grade methanol. Aliquots of each leachate $(20 \mathrm{ml})$ were acidified to $\mathrm{pH} 2$ with trace metal grade $\mathrm{HCl}$ and pipetted through the PPL at a rate not exceeding $10 \mathrm{ml} \mathrm{min}{ }^{-1}$. The appropriate flow rate was achieved using a glass manifold connected to a vacuum pump. After leachates were loaded onto PPL cartridges, $30 \mathrm{ml}$ of dilute trace metal grade hydrochloric acid $(0.01 \mathrm{~N})$ was slowly passed through each PPL to ensure the removal of salts. The PPL cartridges were dried and sealed under nitrogen gas (foil-wrapped in individual $\mathrm{N}_{2}$-filled zip-top bags) and stored in a $-20^{\circ} \mathrm{C}$ freezer until elution with $8 \mathrm{ml} \mathrm{HPLC}$-grade methanol.

\section{BPCA Analysis}

Following Dittmar (2008), eluents were blown down to $0.5 \mathrm{ml}$ under $\mathrm{N}_{2}$ gas at $45^{\circ} \mathrm{C}$, and transferred in methanol into ampules (Wheaton: $1 \mathrm{ml}$, gold band, pre-scored) via glass pipettes and blown to dryness. For solids, $\leq 5.0 \mathrm{mg}$ of finely powdered sample were weighed into glass ampules. Approximately $0.5 \mathrm{ml}$ concentrated nitric acid was added to each ampoule. Then, ampoules were flame-sealed, and placed into Teflon-lined Parr steel bombs that were held in a $170^{\circ} \mathrm{C}$ furnace for $9 \mathrm{~h}$. Approximately $3 \mathrm{ml}$ tap water was added to the Teflon liner to prevent the ampoules from rupturing.

\section{High Performance Liquid Chromatography Analysis}

Following acid oxidation, samples were dried under $\mathrm{N}_{2}$ gas at $45^{\circ} \mathrm{C}$, and methanol-transferred into $2 \mathrm{ml}$ high-recovery HPLC vials (Fisherbrand, 60180-508, with PTFE septa). BPCA compounds were detected on a Shimadzu HPLC (LC-20 Prominence Series) equipped with a C18 column $(3.5 \mu \mathrm{m}, 2.1$ $\times 150 \mathrm{~mm}$, Waters Sunfire) and a diode array detector (DAD) (Surveyor, Thermo-Scientific, SPD-M20A) with a binary gradient program as described in the SI section.

\section{Solid-State ${ }^{13} \mathrm{C}$ NMR Spectroscopy (Solids)}

Solid biochar and reference materials samples were transferred to a $4 \mathrm{~mm}$ rotor covered with a Vespel cap for solid-state ${ }^{13} \mathrm{C}$ NMR analysis using a multiple cross-polarization magic angle spinning (multiCPMAS) pulse sequence (Johnson and SchmidtRohr, 2014). Experiments were conducted on a Bruker Avance II instrument with ${ }^{1} \mathrm{H}$ resonating at $400 \mathrm{MHz}$ and ${ }^{13} \mathrm{C}$ resonating at $100 \mathrm{MHz}$. Samples were spun at the magic angle $\left(54.7^{\circ}\right)$ and at a frequency of $18 \mathrm{MHz}$. The continuous pulses were optimized at
$0.5 \mathrm{~s}$ and a $1 \mathrm{~s}$ recycle delay was used. All sample spectra ( $1,600 \mathrm{co-}$ added scans) were baseline-corrected and calibrated to a glycine external standard (176.03 ppm).

To simplify data comparisons, sample spectra were divided into chemical shift ranges characteristic of carbon moieties typical of natural OM and chars. "Alkyl-C" 0-110 ppm, consists of methyl, methylene, alkyl-O, and di-O-alkyl C. "Aryl-C" refers to $110-146$ ppm: $\mathrm{C}$ in aromatic rings $(\mathrm{C}=\mathrm{C}, \mathrm{Ar}-\mathrm{C}-\mathrm{H})$. "O-aryl C" refers to $146-165 \mathrm{ppm}$ : $\mathrm{C}$ in aromatic rings attached to $\mathrm{O}$ atoms including phenolic groups. Lastly, "carbonyl C" refers to the sum of 165-220 ppm: carboxyl, amide, ester, aldehyde and ketone C. More in-depth categorization of these ${ }^{13} \mathrm{C}$ NMR groups can be found in Table S3. The relative contributions (\% of total spectral signal) from major $\mathrm{C}$ moieties present in each sample were obtained by integrating the spectral signal over each chemical shift region using Bruker Topspin software, and divided by that of the entire spectral region (0-220 ppm).

\section{${ }^{1} \mathrm{H}-\mathrm{NMR}$ Spectroscopy (Leachates)}

Leachates were diluted with $\mathrm{D}_{2} \mathrm{O}(100 \%$ atomic $\mathrm{D}$, Acros Organics) at a volumetric ratio of 9:1 (i.e., $\mathrm{H}_{2} \mathrm{O}: \mathrm{D}_{2} \mathrm{O}$ ) immediately prior to ${ }^{1} \mathrm{H}$ NMR analysis. Deuterated solution ${ }^{1} \mathrm{H}$ NMR spectra were obtained on a Bruker Biospin Avance III 400 $\mathrm{MHz}$ NMR with a BBI probe using a water suppression technique following previous studies (e.g., Wozniak et al., 2013; Willoughby et al., 2016) at Old Dominion University's COSMIC facility. Each sample was scanned at least 4,000 times to obtain an integrated spectrum detecting non-exchangeable $\mathrm{H}$. Scan numbers were increased for samples with lower DOM concentrations to ensure a high enough signal to noise ratio for data interpretation.

The signals obtained from ${ }^{1} \mathrm{H}$ NMR spectra were integrated over specific chemical shift regions that are characteristic of $\mathrm{H}$ chemical environments. The region between 0.60 and $1.80 \mathrm{ppm}$ is referred to as "Alkyl-C" and includes signal from methyl- $\mathrm{H}$ $\left(\underline{\mathrm{H}}_{3} \mathrm{C}\right)$, methylene $\mathrm{H}\left(\underline{\mathrm{H}}_{2} \mathrm{C}\right)$, and $\mathrm{H}$ in alkyl groups that have heteroatoms bound to beta $\mathrm{C}$ ( $\underline{\mathrm{HC}}-\mathrm{C}-\mathrm{CX}$, where $\mathrm{X}$ is $\mathrm{O}, \mathrm{N}, \mathrm{S}$, etc.). The region between 1.85 and $4.4 \mathrm{ppm}$ is referred to as "Oxygenated-C" and includes signal from: $\mathrm{H}$ bound to $\mathrm{C}$ that have alpha $\mathrm{C}$ that are doubly bonded to $\mathrm{C}, \mathrm{O}, \mathrm{N}$, or $\mathrm{S}$ ( $\underline{\mathrm{HC}}$ $\mathrm{C}=\mathrm{Y}$, where $\mathrm{Y}$ is $\mathrm{C}, \mathrm{O}, \mathrm{N}$, or $\mathrm{S}$ including carbonyl and carboxyl functional groups), $\mathrm{H}$ bound to $\mathrm{C}$ bound to $\mathrm{N}, \mathrm{S}$ ( $\underline{\mathrm{HC}}-\mathrm{Z}$, where $\mathrm{Z}$ is $\mathrm{N}$ or $\mathrm{S}$ ), and carbohydrate and alcohol groups ( The region between 6.50 and $8.30 \mathrm{ppm}$ is referred to as "ArylC” and corresponds to $\mathrm{H}$ attached to aromatic C (Ar- $\underline{H})$. Lastly, hydrogens in acetic acid/acetate (1.9-2.1 ppm), methanol (3.2$3.4 \mathrm{ppm})$ and formic acid (8.1-8.3 ppm) appeared in all spectra as sharp peaks indicative of their identification as pure compounds. Signal corresponding to these three regions was summed and reported as "low molecular weight-C" (LMW-C) compounds and subtracted from the Alkyl-C, Oxygenated-C, Aryl- $\mathrm{C}$ regions to which their chemical shifts correspond. Detailed information on categorization of these ${ }^{1} \mathrm{H}$ NMR groups can be found in Table S4. It is important to note that exchangeable $\mathrm{H}$ such as those in carboxylic acid groups $(\mathrm{COO} \underline{\mathrm{H}})$ readily exchange with deuterium in the $\mathrm{D}_{2} \mathrm{O}$ required for analysis and therefore go undetected. Additionally, $\mathrm{H}$ signal between 4.40 and 5.00 ppm, which includes some amine and ester $\mathrm{H}$, is not considered 
because signal in this region is obscured by the water suppression technique. Spectral signals in each chemical shift region were integrated using Bruker Topspin software.

For comparison to the DOC values and ${ }^{13} \mathrm{C}$ NMR data, the ${ }^{1} \mathrm{H}$ NMR spectral integrations which are quantitative for $\mathrm{H}$ signal, were converted to a $\mathrm{C}$ basis by dividing each integrated area by $\mathrm{H} / \mathrm{C}$ ratios typical of the $\mathrm{H}$ environments in that chemical shift region (following, e.g., Decesari et al., 2007): $\mathrm{H} / \mathrm{C}_{\mathrm{H} 3 \mathrm{C}}=$ $3, \mathrm{H} / \mathrm{C}_{\underline{H} 2 \mathrm{C}}=2, \mathrm{H} / \mathrm{C}_{\underline{\mathrm{HC}}-\mathrm{C}-\mathrm{CX}}=2, \mathrm{H} / \mathrm{C}_{\mathrm{HC}=\mathrm{C}-\mathrm{Y}, \underline{\mathrm{HC}}-\mathrm{Z}}=2$, $\mathrm{H} / \mathrm{C}_{\mathrm{HC}-\mathrm{OR}}=1.1, \mathrm{H} / \mathrm{C}_{\mathrm{HC}}=\mathrm{C}=0.4, \mathrm{H} / \mathrm{C}_{\mathrm{H}-\mathrm{Ar}}=0.3, \mathrm{H} / \mathrm{C}_{\mathrm{HC}=\mathrm{O}}$ $=1$. The relative contribution of each chemical shift region was then calculated as the $\mathrm{C}$-basis area divided by the sum of all $\mathrm{C}$ basis areas.

\section{Data Analysis}

The molecular distributions of BPCA molecular markers have been used to infer the degree of aromatic condensation (or aromatic cluster size) in pyOM (Hammes et al., 2007; Schneider et al., 2009, 2010; Ziolkowski and Druffel, 2010; Ziolkowski et al., 2011). Smaller condensed clusters produce benzenetricarboxylic acids (B3CAs) and benzenetetracarboxylic acids (B4CAs); whereas benzenepentacarboxylic acid (B5CA) and benzenehexacarboxylic acid (B6CA) are thought to only form from the central aromatic rings of large aromatic clusters (Schneider et al., 2009; Ziolkowski and Druffel, 2010; Ziolkowski et al., 2011). Thus, greater proportions of B5CA and B6CA have been suggested to indicate higher degrees of condensation in each sample.

Following Ziolkowski and Druffel (2010) and Schneider et al. (2011), we calculate the average number of carboxyl groups present among the BPCA compounds produced by a sample (Equation 1):

$$
\text { BACon }=\frac{(6) \cdot[\mathrm{B} 6 \mathrm{CA}]}{\sum[\mathrm{BPCA}]}+\frac{(5) \cdot[\mathrm{B} 5 \mathrm{CA}]}{\sum[\mathrm{BPCA}]}+\frac{(4) \cdot[\mathrm{B} 4 \mathrm{CA}]}{\sum[\mathrm{BPCA}]}+\frac{(3) \cdot[\mathrm{B} 3 \mathrm{CA}]}{\sum[\mathrm{BPCA}]}
$$

where $\Sigma[\mathrm{BPCA}]$ is the sum of B3CAs, B4CAs, B5CA, and B6CA molar abundance. This BPCA Aromatic Condensation (BACon) Index spans from 3.0 (least condensed; produces only B3CAs) to 6.0 (fully condensed; produces only B6CAs; Ziolkowski and Druffel, 2010).

Oak-400 and Oak-650 leachates were produced in triplicate to gauge the variability in pyDOC production and BPCA analysis reproducibility. All DOC analyses were run in quintuplicate and were re-run if coefficients of variation were $>5 \%$. Bar chart values display the average value of these replicates and error bars represent one standard deviation of values observed. Correlation and statistics between parameters were calculated using the Microsoft Excel (MS, 2010) data analysis tool pack.

\section{RESULTS}

\section{Chemistry of Parent Pyrogenic and Reference Solids}

Elemental composition (i.e., $\% \mathrm{OC}, \% \mathrm{H}, \% \mathrm{~N}, \% \mathrm{O}$, and $\%$ ash and \%volatile matter) of biochars and reference solid materials are provided in Table S1. Compared to their non-pyrolyzed feedstocks, pyrolyzed products were more C-rich and relatively depleted in $\mathrm{N}, \mathrm{H}$, and $\mathrm{O}$. In general, these heteroatoms were progressively lost with increased heating temperature and duration. Consequently, high-temperature biochars (525$\left.650^{\circ} \mathrm{C}\right)$ were much more carbonaceous $(\sim 80-94 \% \mathrm{C})$ than lowtemperature $\left(250-400{ }^{\circ} \mathrm{C}\right)$ chars $(\sim 56-71 \% \mathrm{C})$. These elemental trends are commonly observed in pyrogenic solids (Baldock and Smernik, 2002; Czimczik et al., 2002; Zimmerman, 2010). While the organic C yield was measured only in the "Early" and "Late" leachate (Figure 1), the proportion of total C lost during the entire leaching of the pyrogenic solids (soluble $\mathrm{C}$ ) was estimated to have ranged from $0.2 \%$ (Oak-650, 24 h) to $7.4 \%$ (Oak-250) (see Table S2).

\section{${ }^{13} \mathrm{C}$ NMR Analysis of Parent Solids}

Trends in biomass and biochar solid functional group composition, as determined by ${ }^{13} \mathrm{C}-\mathrm{NMR}$ (Figure 2 and
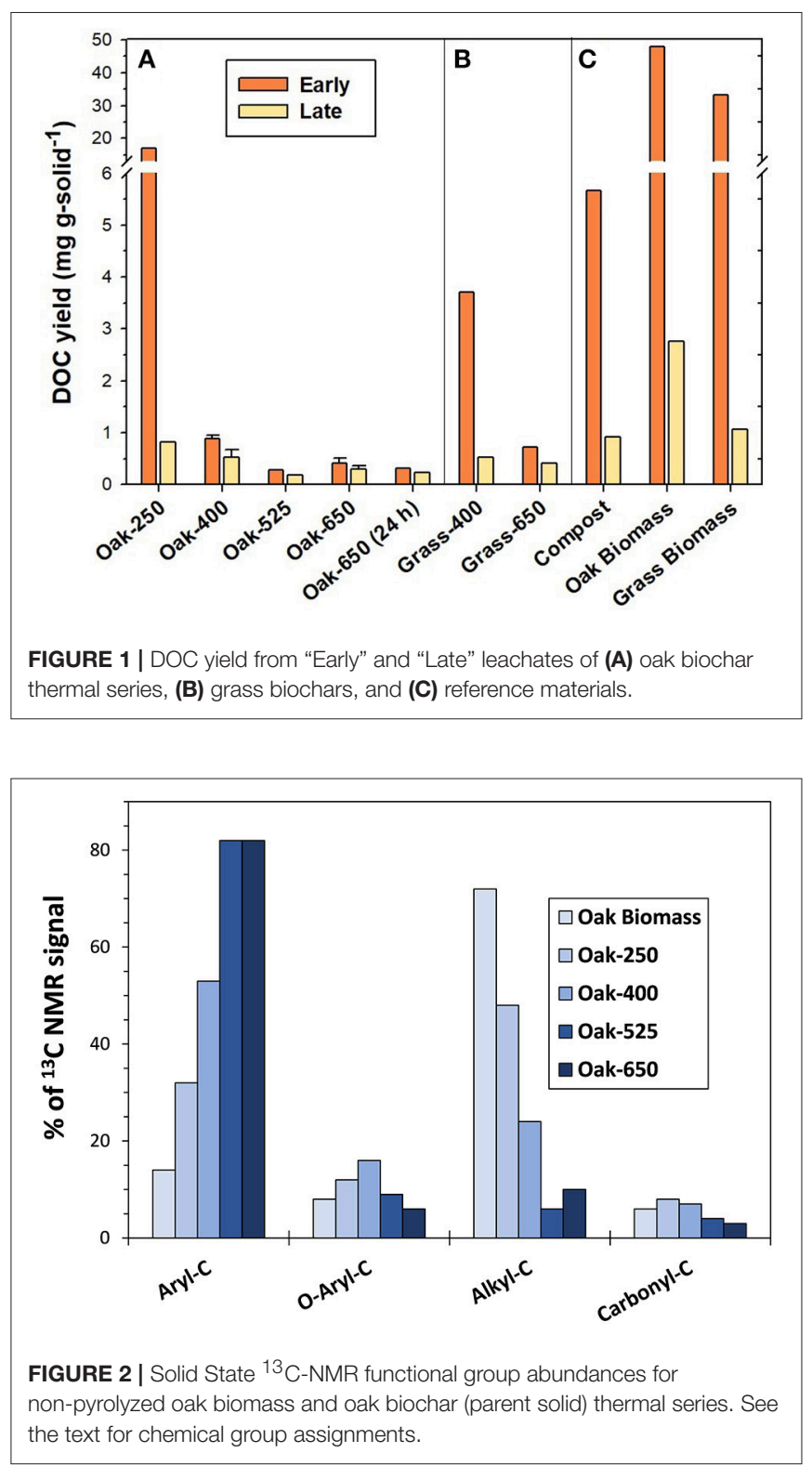
Table S3) were like those observed previously (Hockaday et al., 2007; McBeath et al., 2011, 2014; Cao et al., 2012; Kim et al., 2012; Li et al., 2013). As expected, oak biochars became increasingly rich in aromatic- $\mathrm{C}$ with increasing pyrolysis temperature (from 32 to $82 \%$ of the identified functional groups), a property also seen in grass biochars (data not shown). Correspondingly, higher temperature biochars contained less oxygenated and aliphatic functional groups (methyl, O-alkyl, and carboxyl groups) than lower temperature ones. However, grass biochars had less aromatic $\mathrm{C}$ and more $\mathrm{O}$-containing functional groups than oak biochars made at the same temperature (e.g., 19\% less aryl C for $400^{\circ} \mathrm{C}$ biochar).

\section{BPCA Analysis of Parent Solids}

The proportion of OC in parent pyrogenic solids that yielded BPCA-C ranged from 7.0 to $12.1 \%$ (Figure 3). As expected, given the ${ }^{13} \mathrm{C}$-NMR-determined increase in aromaticity, BPCA-C yield generally increased with pyrolysis temperature. However, the portion of BPCA-C produced by Oak-650 (24h) was lower, a trend comparable to that of other charcoal BPCA studies (e.g., Hammes et al., 2006; Schneider et al., 2010) where less of the $\mathrm{C}$ in very high-temperature chars and soots $\left(800-1,000^{\circ} \mathrm{C}\right)$ was converted to BPCA-C than from intermediate temperature chars. However, graphene oxide and carbon nanotubes showed the highest yields of BPCA-C (20.4 and $15.1 \%$, respectively), similar to other graphitic materials (Dittmar, 2008; Ziolkowski and Druffel, 2009; Schneider et al., 2010); This is likely because they contain relatively more ConAC, but also, the B5CA and B6CA which they produce are less likely to be nitrated during digestion than B3CA and B4CA (Ziolkowski et al., 2011) and thus, not quantified. Thus, it appears that turbostratic graphene structures have lower conversion efficiencies ( $\mathrm{pyC}$ to BPCA-C) than that of graphene oxide sheets.

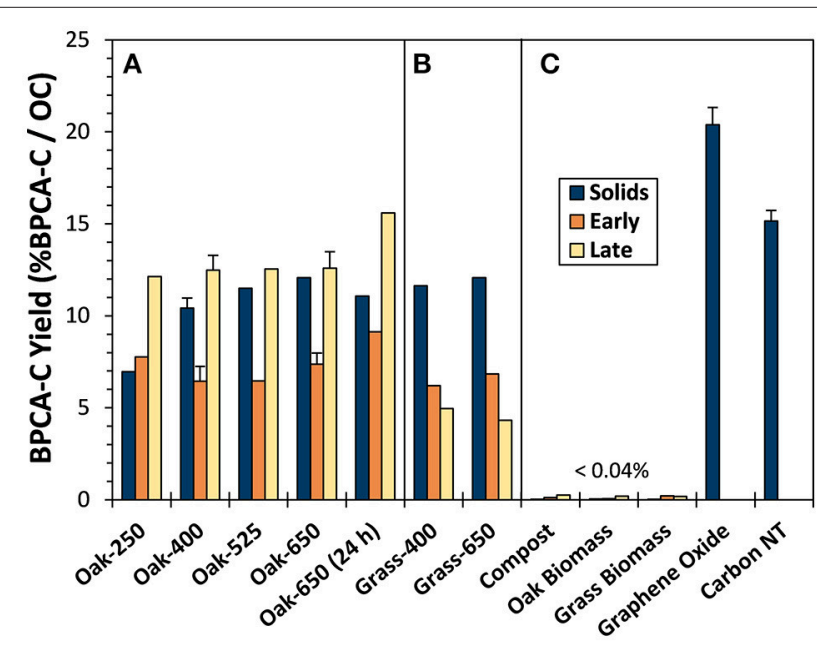

FIGURE 3 | BPCA-C yield from (A) oak char thermal series, (B) grass chars, and $\mathbf{( C )}$ reference material solids and leachates during days 1 and 2 ("Early") and days 16 and 17 ("Late").
The degree of carboxylation in BPCAs from biochar solids, as represented by the BACon Index, increased with pyrolysis temperature (3.7-4.8 for the oak series and 4.3-4.8 for the grass series) (Figure 4). These trends in BACon suggest an increase in ConAC cluster size as chars become more thermally mature, (as observed by others Hammes et al., 2007; Schneider et al., 2010). The highest BACon values calculated were produced by the highly condensed graphene oxide (5.7) and carbon nanotubes (5.2), and were like that of another carbon nanotube BPCA study (e.g., about 5.7, Ziolkowski and Druffel, 2009).

Biomass and compost yielded low amounts of BPCAs $\left(<0.05 \%\right.$ BPCA-C $\left.\mathrm{OC}^{-1}\right)$, suggesting that BPCAs are not exclusive indicators of pyrogenic materials. However, only B3CAs and a few B4CAs were produced from non-pyrolyzed biomass, resulting in BACon values between 3.2 and 3.3, and indicating that if aromatic clusters do exist in these nonpyrogenic solids, they are likely very small or that the digestion step transforms some portion of biomass components into B3CAs and B4CAs.

\section{Yield and Composition of Pyrogenic and Reference Solid Leachates DOC Yield}

Non-pyrolyzed plant biomass produced 33.1-47.9 mg C gsolid $^{-1}$ in "Early" leachates (Figure 1). The "Early" compost leaching yielded considerably less DOC than the oak and grass biomass leachates (about $80 \%$ less) as it had probably been leached by rainfall in the field prior to collection. The DOC yield in "Early" leachates of low-temperature biochar (Oak-250) was

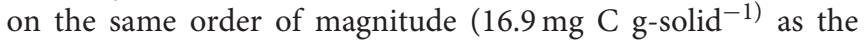
biomass materials. Biochars produced at higher temperatures had DOC yields that were one to two orders of magnitude lower than those of biomass leachates, ranging from only 0.3 to $0.9 \mathrm{mg}$ $\mathrm{C}$ g-solid $^{-1}$ for oak biochars and $0.7-3.7 \mathrm{mg} \mathrm{C}$ g-solid $^{-1}$ for grass biochars made at $400-650^{\circ} \mathrm{C}$ (Figure 3). After 16 days of leaching, the "Late" DOC yield had decreased by about $95 \%$ for the low-temperature biochars by $25-40 \%$ for high-temperature biochars, compared to their "Early" leachate DOC yield.

These py-DOC production trends are similar to those observed previously in other biochar leaching experiments (Mukherjee and Zimmerman, 2013) and were anticipated given the greater abundance of more-soluble components in low temperature and grass chars (e.g., more O-rich functional groups as determined via ${ }^{13} \mathrm{C}-\mathrm{NMR}$ and elemental analyses and lesser condensed fraction as determined by BPCA analysis).

The observation that the most leachable (low T) biochars showed the greatest decreases in pyDOC production over time (with leaching extent), while less leachable chars retained their $\mathrm{C}$ loss rates, suggests that, over time, pyDOM production rates from different charcoal types may become similar to each other due to rapid loss of highly leachable portions and environmental oxidation of less leachable portions (making them more soluble).

\section{${ }^{1} \mathrm{H}-\mathrm{NMR}$ Analysis of pyDOM}

${ }^{1} \mathrm{H}-\mathrm{NMR}$ analysis of biochar leachates revealed generally increasing proportions of aromatic and alkyl components with increasing pyrolysis temperature of their parent solids (Figure 5, 


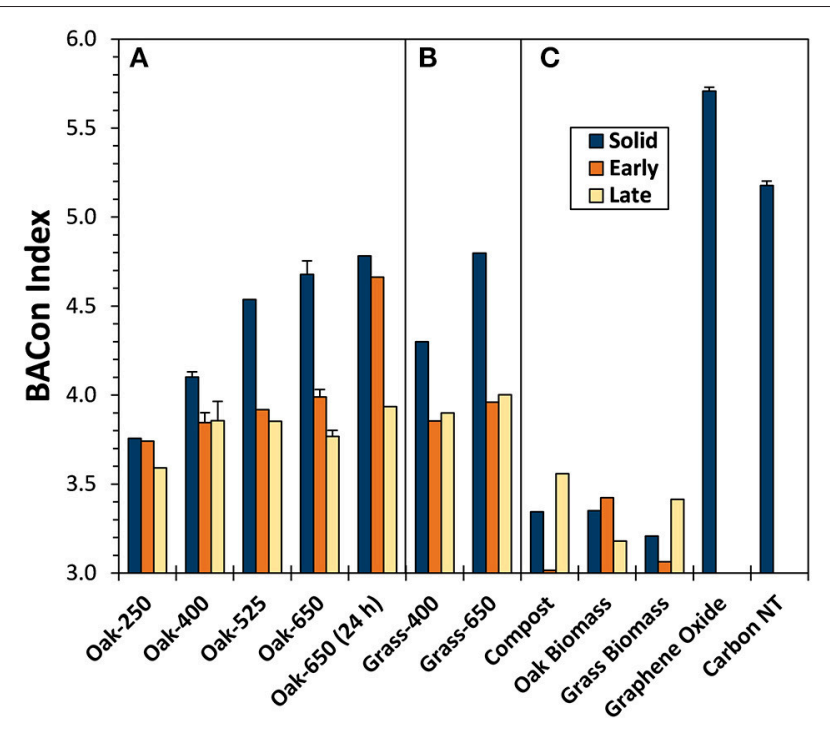

FIGURE 4 | BPCA aromatic condensation (BACon) index values for biochar solids and "Early" and "Late" leachates of (A) oak char thermal series, (B) grass chars, and (C) reference materials.

Table S4). Correspondingly, proportions of oxygenated functional groups (e.g., ether, ester, carbohydrate, and alcohol groups) decreased with increasing parent thermal maturity. The same relationship between aromaticity and temperature was observed in grass biochar leachates (Table S4). However, the aromatic portion was much higher in grass biochar leachates than in oak biochar leachates (e.g., $22 \%$ vs. $10 \%$ aryl $\mathrm{C}$ for Grass-400 and Oak-400 leachate, respectively). An exception to these trends was the "Early" leachate of Oak-250, which was more aromatic than the higher temperature biochars. This is most likely because of contributions from the ligninaceous components of the wood biomass that remained at this low treatment temperature. Aromatic compounds made up $14 \%$ of the ${ }^{13} \mathrm{C}$-NMR signal of non-pyrolyzed oak biomass and $10 \%$ of the ${ }^{13} \mathrm{C}-\mathrm{NMR}$ signal of non-pyrolyzed grass biomass. Among these, low molecular weight oligomers of lignin may be among the more soluble components in wood. The LMW-C compounds become much more abundant in leachates upon heating of parent solids from 250 to $400^{\circ} \mathrm{C}$ while contributions from aryl-C are decreased considerably (Figure 5) suggesting that phenolic compounds from lignin may be the predominant source of the LMW-C compounds. The LMW-C compounds may have been mineralized to carbon dioxide or volatilized upon pyrolysis at higher temperatures.

\section{BPCA-C Yield From pyDOM and Reference Leachates}

The proportions of total $\mathrm{C}$ converted to BPCA (i.e., the BPCA-C yield) in "Early" and "Late" biochar leachates were similar to that of solid biochars, with most in the range of 7-12\% BPCA-C/OC (Figure 3, Tables S2, S5). However, some differences were apparent. Oak biochar "Late" leachates were always somewhat enriched in BPCA-producing compounds compared to either their parent solids or "Early" leachates (by 20 and $43 \%$ on average, respectively). This may be attributed to the presence of non-condensed OM in the solids and "Early" leachates that was progressively lost with leaching. In contrast, this increase in \%BPCA-C/DOC with leaching did not occur in the grass biochars, possibly because the noncondensed OM of grass chars, being much more abundant, was still being released even after many leaching cycles. While BPCA-C yield from non-pyrogenic reference leachates were low on a per DOC basis $(<0.04 \%)$, compost and the biomasses produced as much BPCA-C as oak-400 on a per $\mathrm{g}$ parent solid basis.

\section{Molecular Distribution of BPCA in pyDOM}

Trends in the varying proportions of the eight BPCA compounds produced upon oxidation of the biochar leachates (Table S5) are represented by their BACon values (Figure 4). Pyrogenic leachates usually had lower BACon values than their parent solids. BACon values of "Early" and "Late" leachates were, in most cases, quite similar, as were those of grass and oak biochar leachates from parent solids of the same charring temperature (BACon values $\approx 3.8$ ). Unlike the parent solids, biochar leachate BACon values increased only slightly with parent solid pyrolysis temperature (e.g., from 3.7 to 4.0 for "Early" Oak-250 and Oak-650, respectively). Thus, it can be inferred that the size of aromatic clusters in pyDOM were relatively constant, even as the ConAC content and aromatic cluster size of its parent solids increased with thermal maturity.

The "Early" leachate of Oak-650 (24 h) had an anomalously high BACon value for which we have no explanation other than to speculate that a small amount of colloidal pyOM with composition very similar to the parent biochar solid may have entered the filtrate. This proposed shift in composition would have been all the more likely in this sample of very low DOC content.

The pyDOM produced in this study had BACon values that were similar to that of aged chestnut char leachate described previously (about 4.0, Abiven et al., 2011). Further, BACon values of char leachates (e.g., this study, Abiven et al., 2011; Roebuck et al., 2017; Wagner et al., 2017) resembled those of natural DOM from the Gulf of Mexico (about 4.3, Dittmar, 2008), ultrafiltered Amazon River water (about 4.0, Ziolkowski and Druffel, 2010), and the open ocean (about 3.8, Ziolkowski and Druffel, 2010). A possible explanation is that condensed $\mathrm{OM}$ is uniformly susceptible to degradation, regardless of cluster size. Alternatively, several environmental degradation pathways could affect BACon values of DOM in opposing ways. Photodegradation may oxidize larger aromatic clusters into smaller aromatic clusters, resulting in lower BACon values, while preferential microbial consumption of smaller aromatic clusters may result in a higher BACon value.

As with their parent solids, the reference biomass and compost leachates contained only B3CAs and B4CAs (about $0.05-0.2 \%$ in "Early" and about $0.2-0.3 \%$ BPCA-C/DOC in "Late" leachates). While these BPCA-C yields were very low on an OC basis, their increase over time is notable. Furthermore, on a weight basis, 


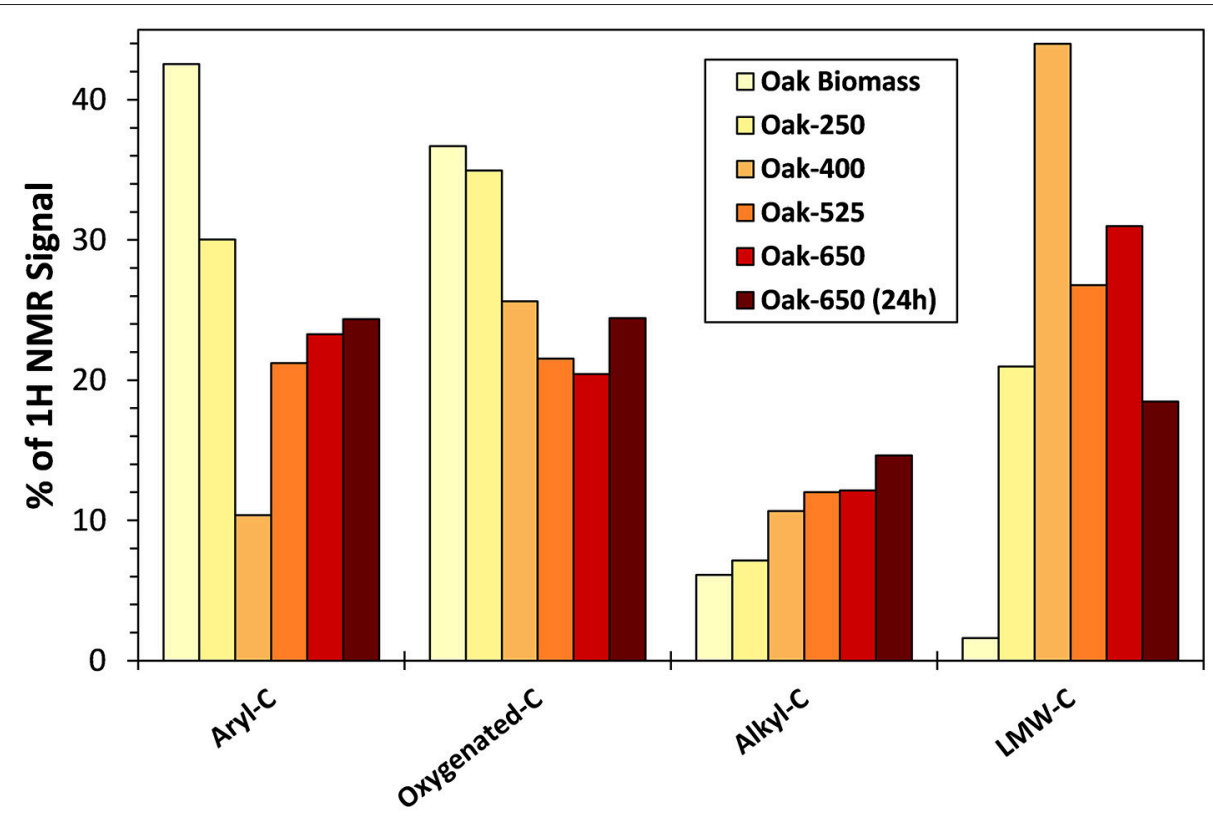

FIGURE 5 $\mid{ }^{1} \mathrm{H}$-NMR functional group abundances in "Early" leachates of oak biomass and its biochar thermal series, calculated on a carbon basis. See the text for chemical group assignments.

amounts of B3CAs and B4CAs produced from non-pyrogenic leachates were similar to that of parent pyrogenic materials (discussed further below).

\section{DISCUSSION}

\section{Pyrogenic C Quantification Implications Non-pyrogenic BPCA Production}

In this study, solid non-pyrogenic solids (oak biomass, grass biomass, and compost) and their leachates were shown to produce B3CAs and B4CAs upon nitric acid digestion. The production of BPCAs from the oxidation of natural "humic" substances, using both $\mathrm{HNO}_{3}$ and alkaline- $\mathrm{KMnO}_{4}$ techniques, has long been noted, and was proposed to have been produced by the destruction of aromatic rings with oxygen-containing side chains, as well as from ConAC (Hansen and Schnitzer, 1967; Stevenson, 1994). More recently, it was suggested that even aromatic rings with aliphatic side chains (e.g., retene) can produce BPCA-C (Ziolkowski et al., 2011). Perhaps this is why Kappenberg et al. (2016) observed BPCA production (even B6CA) from pyC-free corn stalks (Zea mays) and leaves of pepper plants (Capsicum annuum), when enough sample was processed (>8.7 mg C). This may also explain why, using total BPCA as an indicator, the greatest concentrations of "pyDOC" have been reported for peat-influenced sloughs and rivers that contain large amounts of humic-like DOM (Ziolkowski and Druffel, 2010; Jaffé et al., 2013).

An additional issue is that many B3CAs and B4CAs (produced by less condensed pyC) are more likely nitrated during the nitric acid digestion step. As these are not quantified by HPLC-DAD, this further complicates the usage of $\mathrm{B} 3 \mathrm{CA}+\mathrm{B} 4 \mathrm{CA}-\mathrm{C}$ as a marker of ConAC. More investigations are needed to identify the organic matter fraction targeted by total BPCA analysis.

In our study, B5CA and B6CA was not produced from reference materials (even when digesting samples with more than $5 \mathrm{mg} \mathrm{C}$ ). Thus, we agree with Kappenberg et al. (2016) that B5CA+B6CA-C, and only B5CA+B6CA-C, can be used as a quantitative marker for ConAC, and by inference, the condensed aromatic portion of $\mathrm{pyC}$, as we have done below.

\section{Estimating ConAC From B5CA+B6CA-C}

The B5CA+B6CA-C yields from oak biochar solids ranged from 2.5 to $7.1 \%$ (Figure 6, left axis). Unlike total BPCA-C yield, B5CA+B6CA-C yield from the biochar solids was consistently greater than that of their leachates, which ranged from $0.9 \%$ (Oak-250) to $4.4 \%$ (Oak-650, $24 \mathrm{~h}$ ). In addition, both solid and leachate $\mathrm{B} 5 \mathrm{CA}+\mathrm{B} 6 \mathrm{CA}-\mathrm{C}$ yields increased more consistently with pyrolysis temperature than total BPCA-C yield. Finally, B5CA+B6CA-C yields of "Early" and "Late" leachates were more similar than those of total BPCA-C. These trends, along with the lack of production of B5CA and B6CA from solids and leachates of non-pyrolyzed biomass, suggest that B5CA and $\mathrm{B} 6 \mathrm{CA}$ are indeed better markers for pyrogenic $\mathrm{C}$ than total BPCAs. However, because B5CA and B6CA likely do not form from non-condensed or the small ( $<5$ aromatic rings) condensed clusters of pyrogenic OM, it is certainly a more conservative estimate of ConAC and potentially pyC.

We used the $\mathrm{B} 5 \mathrm{CA}+\mathrm{B} 6 \mathrm{CA}-\mathrm{C}$ yield from graphene oxide (14.2\%), assumed to only contain condensed aromatic C, to generate a conversion factor to calculate the ConAC content of each pyrogenic sample (i.e., ${ }^{100 / 14.2}=7.04$ ). Using this approach, the ConAC content of the solid biochars was calculated to 


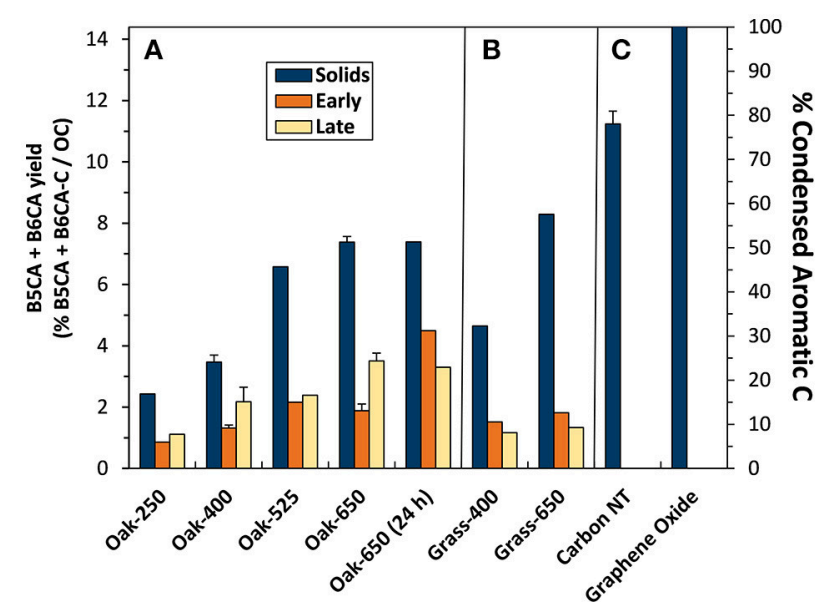

FIGURE 6 | Benzene penta- and hexa-carboxylated acid (B5CA + B6CA)-C yield (left axis) and calculated condensed aromatic $\mathrm{C}$ abundance (right axis) in biochar solids and "Early" and "Late" leachates of (A) oak char thermal series, (B) grass chars, and $\mathbf{( C )}$ reference materials.

range from $16 \%$ in Oak-250 to $51 \%$ in Oak-650 (Figure 6, right axis). These ConAC proportions (as quantified with B5CAs and B6CAs) represent approximately half of the aryl-C content indicated by ${ }^{13} \mathrm{C}-\mathrm{NMR}$ analysis, suggesting that about half of the aromatics in biochars may be non-condensed aromatics (e.g., lignin oligomers). For example, whereas ${ }^{13} \mathrm{C}-\mathrm{NMR}$ assigned $53 \%$ of the $\mathrm{C}$ in Oak-400 as aromatic, $24.2 \%$ was estimated to be ConAC using the B5CA+B6CA-C calculation method. Similarly, pyrogenic oak leachates $\mathrm{C}$ ranged from about 6 to $31 \%$ ConAC (in "Early" Oak-250 to "Early" Oak-650 (24 h) respectively), with "Late" leachates falling in a similar range. The ConAC content of leachates was also approximately half that assigned by ${ }^{1} \mathrm{H}$ NMR as aromatic C. The other half of aromatic $\mathrm{C}$ in leachates and solids could be in the form of non-condensed or small (cluster sizes $<5$ aromatic rings) condensed structures that do not form $\mathrm{B} 5 \mathrm{CA}+\mathrm{B} 6 \mathrm{CA}-\mathrm{C}$ or from olefinic carbons that overlap the aromatic $\mathrm{C}$ region of the NMR spectrum but do not form BPCAs. From these calculations, it can be further estimated that, whereas the biochars released $0.2-7.4 \%$ of their $\mathrm{C}$ during the experiment, only $0.1-3.0 \%$ of the solid ConAC was lost via dissolution.

\section{Estimating pyDOC From ConAC}

BPCA-C analysis detected $14.2 \%$ of the ConAC in graphene oxide (C is composed of $100 \%$ ConAC), arriving at a multiplication factor of 7.04 required to convert B5CA+B6CA-C amounts to ConAC. However, based on the finding that ConAC represented $5-24 \%$ of the total pyDOC, an additional multiplication factor of $4-20$ is still required to convert ConAC to total pyDOC. However, if one was using this ConAC to pyDOC conversion factor, one would need to assume that all ConAC is pyrogenic. In addition to the large margins of error that would thus be expected to be associated with these ConAC to pyDOC conversion factors, further caution should be exercised because different pyrogenic solids (biochars) were shown to produce pyDOM with different non-ConAC:ConAC ratios. To make
pyDOM quantification even more difficult, in nature, the nonConAC:ConAC ratio in pyDOM is also likely to be altered by variable abiotic and biotic degradation, timing and extent of leaching, variable mineral/particulate interactions, and a variety of other factors. Together, these uncertainties will make the elucidation of the pyDOM cycle a very challenging task.

\section{Controls on PyDOM Release}

An overall finding of this study is that pyrogenic leachates are compositionally dissimilar to their respective parent solids. Although the similar yield of total BPCA-C from parent solids and leachates (Figure 3) suggests a similar ConAC content, a closer examination of the molecular distribution of BPCA compounds shows that this resulted from the co-occurrence of decreases in the abundance of B3CA- and B4CA-producing compounds (Figure S1) and increases in the abundance of B5CAand B6CA-producing compounds (Figure 6) in the leachates with increasing thermal maturity of their pyrogenic parent solids. Moreover, the proportion of $\mathrm{B} 5 \mathrm{CA}+\mathrm{B} 6 \mathrm{CA}-\mathrm{C}$, and calculated BACon values and ConAC contents were greater in parent solids than their leachates (Figures 4, 6). Higher temperature (525$650^{\circ} \mathrm{C}$ ) biochar leachates produced only about half as much $\mathrm{B} 5 \mathrm{CA}+\mathrm{B} 6 \mathrm{CA}-\mathrm{C}$ as their parent solids (on a per OC basis) with no consistent trends distinguishing "Early" and "Late" leachates.

Distributions of non-aromatic constituents $(10-56 \%$ of pyrogenic solid C vs. $63-88 \%$ of their leachates) also suggested that pyDOM is of different composition than its solid pyOM parent. For example, while aliphatic- $\mathrm{C}$ represented similar proportions of total $\mathrm{C}$ in the pyrogenic solids and their leachates (10-30\% excluding the $250^{\circ} \mathrm{C}$ biochar), this proportion decreased in the solids and increased in the leachates along the pyrolysis temperature gradient. Leachates of Oak-250 biochar had anomalously high aryl-C relative abundance, while its parent solid did not. However, these differences could have been driven by the pattern of LMW compounds that were separately quantified in the leachates but not the solids. Caution should be used when interpreting ${ }^{1} \mathrm{H}-\mathrm{NMR}$ aromaticity data, especially when samples contain large condensed moieties, as these are largely undersaturated with hydrogen and are difficult to quantify as aryl-C. Finally, it must be noted that comparisons between ${ }^{13} \mathrm{C}-\mathrm{NMR}$ and ${ }^{1} \mathrm{H}-\mathrm{NMR}$ data are imperfect because functional group classifications are not identical.

In order to further examine the controls on the solubility of BPCA-producing components in pyC, solid-liquid distribution coefficients, defined here as the ratio of the amount of a component in the solid to the amount in its leachate, were calculated for both the bulk pyC and ConAC yielding B5CA-C and B6CA-C (i.e., $\mathrm{K}_{\mathrm{D}}$, pyC and $\mathrm{K}_{\mathrm{D}}$, ConAC, respectively). Thus, a greater $\mathrm{K}_{\mathrm{D}}$ indicates relatively lower solubility.

The first notable result was that the $K_{D, p y C}$ and $K_{D}$, ConAC varied by about 1 and 2 orders of magnitude, respectively (Figure 7), again illustrating the wide variations in biochar$\mathrm{C}$ solubility and the distinction between production of total pyC and ConAC. The significant negative correlation of both $\mathrm{K}_{\mathrm{D} \text {,pyC }}$ and $\mathrm{K}_{\mathrm{D}}$, ConAC with $\%$ oxygenated $\mathrm{C}$ in parent solids (Figures 7A,B), and their positive correlation with BACon value of parent solids (Figures 7C,D) show that both functional 

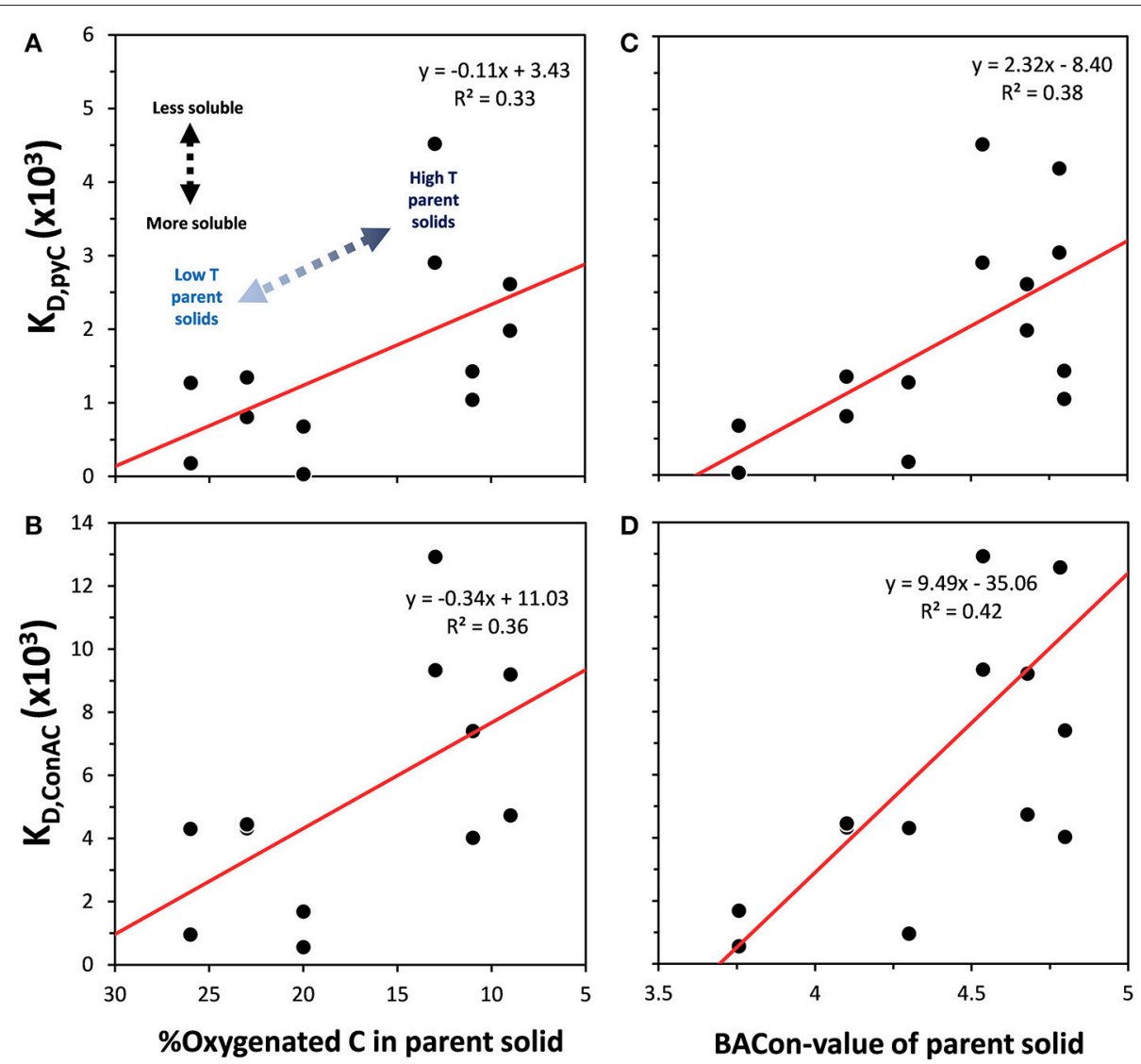

FIGURE 7 | Relationship between the solid-liquid distribution coefficients of bulk pyC and ConAC compounds yielding B5CA-C and B6CA-C (i.e., $\mathrm{K}_{\mathrm{D}}$, pyC and $\mathrm{K}_{\mathrm{D}}$ ConAC, respectively) in "Early" and "Late" leachates and \%C in parent solid O-containing functional groups (A,B, respectively), and aromatic cluster size as indicated by the BACon Index (C,D, respectively). All linear correlations are statistically significant $(p<0.05)$.

group content and aromatic cluster size control pyC solubility. The data generated here do not support a greater role of either factor or a greater influence on either the condensed or non-condensed portion of pyC (all correlation coefficients were similar: 0.33-0.42). A further indication that bulk pyC and ConAC solubility are controlled by similar factors is the strong correlation between the $\mathrm{K}_{\mathrm{D}, \mathrm{pyC}}$ and each $\mathrm{K}_{\mathrm{D}}$, BPCA-C (i.e., partitioning coefficients of compounds that produce each BPCA) (Figure S2, $r^{2} \sim 0.80, p<0.05$ ). Besides functional group content and aromatic cluster size, other processes that may result in the decrease in solubility with thermal maturity for both pyC and BPCA-producing compounds, include: (1) volatilization and removal of readily-soluble components from the pyOM pores with increasing pyrolysis temperature, (2) a codependence of solubility on the presence of inorganic ions or colloids, and (3) the mutual assistance of condensed and noncondensed pyOM in their solubilization. This latter explanation may be similar to the proposal that non-pyOM assists in the solubilization of condensed portions of pyC (Wagner et al., 2017). A final observation is that while B5CA- and B6CA-producing compounds were much less soluble than bulk pyC (slopes of $\sim 4$ in Figure S2), B3CA- and B4CA-producing compounds were similar to or less soluble than the bulk pyC.
These findings have implications for the use of BPCAs as pyrogenic $\mathrm{C}$ markers in natural samples. First, solid pyC solubility varied greatly along the thermal gradient; a fire's temperature will make a substantial difference in how representative the BPCA method is for quantifying its pyC content and its pyDOC products. While it would be optimal for a dissolved phase chemical marker to have the same solubility as the solid component it traces, the use of B3CAs and B4CAs has a number of disadvantages including their generation from non-pyrogenic processes, as noted above.

\section{Environmental Significance}

These results show that pyrogenic materials (as modeled by laboratory-made biochars) are diverse in both their composition and propensity to release pyDOM. The estimated pyC losses ranged from about $7.5 \%$ for lightly-charred $\left(250^{\circ} \mathrm{C}\right)$ biomass to $0.2 \%$ for higher temperature biochars during the current experiment. The biochar:water ratio ( $1 \mathrm{~g}$ biochar in daily leachings totaling $870 \mathrm{ml}$ over 17 days, see Table S1) is similar to the average global precipitation rate passing through a half meter of soil of an average pyC content (see SI section on "biochar:water ratio"). As a result, if one considers our experiments as having substituted agitation for time, these $\mathrm{C}$ 
releases $(0.2-7.5 \%$ on a pyC basis) may be on the order of annual $\mathrm{C}$ released by biochars in an average soil. In nature, these loss rates might be expected to continue indefinitely due to equilibrium partitioning of compounds between solid and dissolved phases and due to ongoing abiotic and enzymatic oxidation within soils, which assists in solubilizing pyC. PyDOC yields from biochars aged for 9 months in Florida humid air and precipitation, but not sunlight, was found to be similar to those of their unaged counterparts (Mukherjee and Zimmerman, 2013). Additionally, mobilized pyDOC was detected in rivers draining Brazil's Atlantic forest even 40 years after cessation of widespread slash-and-burning (Dittmar et al., 2012a). Given that wildfires are typically in the upper range of the temperatures $\left(500-700^{\circ} \mathrm{C}\right)$ used to produce our biochars (Santin et al., 2015), and $60 \%$ of riverine organic DOC derives largely from forested (not grassy) catchments (Hedges et al., 1997), we have weighted the results (30\% Oak-400, 30\% Oak-650, 20\% Grass-400, 20\% Grass-650) to arrive at a global estimate of annual pyDOC release from pyrogenic solids of about $0.9 \%$ of the total pyC pool (calculation shown in SI section). This is probably an underestimate if one considers that our experiments did not allow for charcoal surface colonization by microbial and associated enzymatic oxidation or photodegradation, which would solubilize formerly insoluble pyC.

Construction of a simple pyC cycling box model can help to identify "knowns" and "unknowns" in our understanding of pyDOC transfers between soil and fluvial reservoirs. Using the commonly-cited soil organic carbon (SOC) stock of 1,600 Pg C (upper $1 \mathrm{~m}$ of soil, Eswaran et al., 1993) and a median value of pyC/SOC measurements of 10\% (e.g., Bird et al., 1999; Hammes et al., 2007; Cusack et al., 2012), the pyC soil stock can be estimated as $160 \mathrm{Pg}$ (Figure 8). Using our estimate of $0.9 \%$ annual pyC leaching, a flux to soil porewater of $1,440 \mathrm{Tg}^{-1}$ pyC is calculated. Using the finding that "pyDOC" represents a constant fraction of about $10.6 \%$ of riverine DOC globally (Ding et al., 2013, 2014; Jaffé et al., 2013) and the annual total riverine

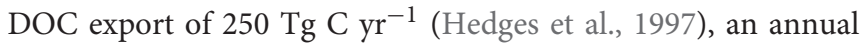
riverine "pyDOC" export of $27 \mathrm{Tg} \mathrm{C}^{-1}$ is calculated (Figure 8). However, the "pyDOC" concentrations measured in these studies were based on BPCA analysis, which, as previously mentioned, only detects ConAC. Because BPCA-C represents only about $13.3 \%$ of total pyDOC (averaged using the same weighting, as above), we can apply a multiplication factor of $7.5(100 / 13.3)$ to scale this leached ConAC flux up to approximately $203 \mathrm{Tg}$ pyDOC delivered to rivers annually.

Several overall conclusions can be made from this box modeling exercise (Figure 8). First, as the pyC leaching flux is much greater than the riverine $\mathrm{C}$ flux, much of the leached pyDOC ( $>86 \%$ ) must be lost in transit. In addition to microbial oxidation, other potential fates of pyDOC include photolytic oxidation and sorption to minerals or particulate OM (i.e., in soil, the vadose zone, or in rivers). However, these processes are yet to be comprehensively quantified.

The results of this study also highlight the chemical diversity of pyDOM, both in the range of compound types leached, and the variations that may be attributed to the different types of pyrogenic parent solids. The majority of pyDOC, especially in "Early" leachates, is not ConAC, which may change our perspective of the overall solubility/lability of pyDOM and our endeavors to quantify it. In nature, these non-ConAC moieties (e.g., pyrogenic alcohols, carbohydrates, aliphatic, and LMW components) are likely more labile than the aromatic components of pyDOM (as inferred from Kalbitz et al., 2003), and thus may fuel heterotrophy in groundwater and surface water systems. Thus, occurrence of fire and the functioning and health of aquatic ecosystems within a watershed may be linked on short timescales.

As for the condensed aromatic portion of pyDOM, it has long been demonstrated that ConAC compounds can be biodegraded by bacteria, lignolytic (Field et al., 1992), and non-lignolytic
Boxes: pyC reservoirs, units of $\mathrm{Tg} C$ Arrows: pyC fluxes, units of $\mathrm{Tg} \mathrm{C}^{-1}$

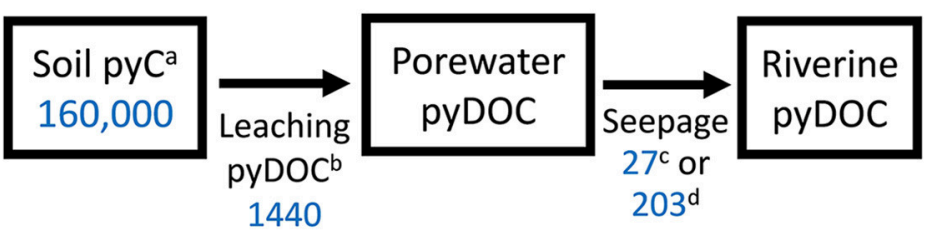

Sources and calculation methods of values shown [and ranges]

a. $\mathrm{pyC} / \mathrm{SOC}=10 \%$ (Mitra et al., 2014) of $1600 \mathrm{Pg} \mathrm{C}$, (Eswaran et al., 1993) [575-3101 Pg

C, Todd-Brown et al., 2013].

b. $0.9 \% *$ of pyC $[0.2-7.4 \%$, this study].

c. pyDOC/DOC $=10.6 \%$ (Jaffé et al., 2013) of $250 \mathrm{Tg} \mathrm{y}^{-1}$ DOC (Hedges et al., 1997).

d. Conversion of ConAC of \#3 (above) to total pyC using factor of 13.3* [6.9-18.7, this study].

*weighted as described in manuscript

FIGURE 8 | Box model of pyC transfer from terrestrial to fluvial systems. 
fungi (Karich et al., 2017), photodegraded (Fasnacht and Blough, 2002; Saeed et al., 2011; Stubbins et al., 2012), and even completely mineralized (Haemmerli et al., 1986; Cerniglia and Heitkamp, 1990; Bezalel et al., 1996a,b,c). The absence of these microbial groups and light may, perhaps, explain the persistence of ConAC in the marine environment where it has been found to be the oldest component of marine DOM (radiocarbon ages of approximately $18,000 \pm 3,000$ years bp, Ziolkowski and Druffel, 2010; Stubbins et al., 2012). As a long-lived C sink, further investigation of the source and fate of long-lived marine ConAC compounds is needed, especially since nonthermogenic processes can also produce ConAC (Chen et al., 2014).

\section{CONCLUSIONS}

By analyzing the leachates of a series of pyrogenic solids generated from both hardwood and grass feedstock with systematic increases in pyrolysis temperature, this study improves our understanding of pyDOM composition and the BPCA method commonly used to quantify pyDOC. The finding that pyrogenic materials are diverse in composition and solubility and that a large portion of pyDOC is non-condensed has implications for pyDOC as it is currently quantified. Pyrogenic OM was shown in this study to be compositionally diverse, dissimilar to its parent pyrogenic solid, and more than half of pyDOC was non-condensed aromatic C. Because of this, we recommend that researchers using the BPCA method state explicitly that they are quantifying ConAC and not pyDOC in their future studies to minimize confusion.

A further implication is that inferences as to pyC source drawn from pyDOM chemical composition may be made only with extreme caution. The solubility of pyC is controlled by parent solid O-containing functional group content and degree of aromatic condensation but is also likely to be highly altered by photolytic, enzymatic, and sorptive processes during mobilization. Future work should examine the effects of these processes on pyDOM mobility and composition as well as the

\section{REFERENCES}

Abiven, S., Hengartner, P., Schneider, M. P. W., Singh, N., and Schmidt, M. W. I. (2011). Pyrogenic carbon soluble fraction is larger and more aromatic in aged charcoal than in fresh charcoal. Soil Biol. Biochem. 43, 1615-1617. doi: 10.1016/j.soilbio.2011.03.027

Baldock, J. A., and Smernik, R. J. (2002). Chemical composition and bioavailability of thermally, altered Pinus resinosa (Red Pine) wood. Org. Geochem. 33, 1093-1109. doi: 10.1016/S0146-6380(02)00062-1

Bezalel, L., Hadar, Y., and Cerniglia, C. E. (1996a). Mineralization of polycyclic aromatic hydrocarbons by the white rot fungus Pleurotus ostreatus. Appl. Environ. Microbiol. 62, 292-295.

Bezalel, L., Hadar, Y., Fu, P. P., Freeman, J. P., and Cerniglia, C. E. (1996b). Initial oxidation products in the metabolism of pyrene, anthracene, fluorene, and dibenzothiophene by the white rot fungus Pleurotus ostreatus. Appl. Environ. Microbiol. 62, 2554-2559.

Bezalel, L., Hadar, Y., Fu, P. P., Freeman, J. P., and Cerniglia, C. E. (1996c). Metabolism of phenanthrene by the white rot fungus Pleurotus ostreatus. Appl. Environ. Microbiol. 62, 2547-2553. initial solubilization of pyC. The ultimate goal would be to balance the global pyC cycle (Figure 8) so that the role of fire and human influence on it (i.e., whether through climate change or intentional pyC production and soil amendment) can be fully understood and incorporated into global C cycling models. Before global-scale inferences can be made about the cycling of pyC, it is important to establish a fundamental understanding of the yield and character of soluble components produced by different pyrogenic materials.

\section{AUTHOR CONTRIBUTIONS}

$\mathrm{KB}$ and $\mathrm{AZ}$ conducted all biochar manufacturing, leaching, DOC analyses, and BPCA analyses. ${ }^{13} \mathrm{C}-\mathrm{NMR}$ and ${ }^{1} \mathrm{H}$-NMR analyses were conducted by AW and $\mathrm{PH}$. All authors listed have made a substantial, direct, and intellectual contribution to the current work, and approved it for this publication.

\section{FUNDING}

This work was funded by the U.S. National Science Foundation Geobiology and Low-Temperature Geochemistry Program (EAR-1451367). Publication of this article was funded in part by the University of Florida Open Access Publishing Fund.

\section{ACKNOWLEDGMENTS}

We thank Dr. Jason Curtis for his help with elemental analyses. Additionally, we thank the UF Geological Science department engineer Dow Van Arnam for helping with construction and maintenance of laboratory apparatus. Alex Goranov and Jim Hall assisted with NMR measurements.

\section{SUPPLEMENTARY MATERIAL}

The Supplementary Material for this article can be found online at: https://www.frontiersin.org/articles/10.3389/feart. 2018.00043/full\#supplementary-material
Bird, M. I., Moyo, C., Veenendaal, E. M., Lloyd, J., and Frost, P. (1999). Stability of elemental carbon in a savanna soil. Global Biogeochem. Cycles 13, 923-932. doi: 10.1029/1999GB900067

Bird, M. I., Wynn, J. G., Saiz, G., Wurster, C. M., and McBeath, A. (2015). The pyrogenic carbon cycle. Annu. Rev. Earth Planet. Sci. 43, 273-298. doi: 10.1146/annurev-earth-060614-105038

Bowman, D. M., Balch, J. K., Artaxo, P., Bond, W. J., Carlson, J. M., and Cochrane, M. A. (2009). Fire in the Earth system. Science 324, 481-484. doi: $10.1126 /$ science. 1163886

Brodowski, S., Rodionov, A., Haumaier, L., Glaser, B., and Amelung, W. (2005). Revised black carbon assessment using benzene polycarboxylic acids. Org. Geochem. 36, 1299-1310. doi: 10.1016/j.orggeochem.2005.03.011

Cao, X., Pignatello, J. J., Li, Y., Lattao, C., Chappell, M. A., Chen, N., et al. (2012). Characterization of wood chars produced at different temperatures using advanced solid-state 13C NMR spectroscopic techniques. Energy Fuels 26, 5983-5991. doi: 10.1021/ef300947s

Cerniglia, C. E., and Heitkamp, M. A. (1990). Polycyclic aromatic hydrocarbon degradation by mycobacterium. Methods Enzymol. 188, 148-153. doi: 10.1016/0076-6879(90)88027-8 
Chen, H. M., Abdulla, H. A. N., Sanders, R. L., Myneni, S. C. B., Mopper, K., and Hatcher, P. G. (2014). Production of black carbon-like and aliphatic molecules from terrestrial dissolved organic matter in the presence of sunlight and iron. Environ. Sci. Technol. Lett. 1, 399-404. doi: 10.1021/ez5002598

Cusack, D. F., Chadwick, O. A., Hockaday, W. C., and Vitousek, P. M. (2012). Mineralogical controls on soil black carbon preservation. Global Biogeochem. Cycles 26, 1-10. doi: 10.1029/2011GB004109

Czimczik, C. I., Preston, C. M., Schmidt, M. W. I., Werner, R. A., and Schulze, E.-D. (2002). Effects of charring on mass, organic carbon, and stable carbon isotopic composition of wood. Org. Geochem. 33, 1207-1223. doi: 10.1016/S0146-6380(02)00137-7

Decesari, S., Mircea, M., Cavalli, F., Fuzzi, S., Moretti, F., Tagliavini, E., et al. (2007). Source attribution of water-soluble organic aerosol by nuclear magnetic resonance spectroscopy. Environ. Sci. Technol. 41, 2479-2484. doi: $10.1021 /$ es0617111

Ding, Y., Cawley, K. M., da Cunha, C. N., and Jaffe, R. (2014). Environmental dynamics of dissolved black carbon in wetlands. Biogeochemistry 119, 259-273. doi: 10.1007/s10533-014-9964-3

Ding, Y., Yamashita, Y., Dodds, W. K., and Jaffé, R. (2013). Dissolved black carbon in grassland streams: is there an effect of recent fire history? Chemosphere 90 , 2557-2562. doi: 10.1016/j.chemosphere.2012.10.098

Dittmar, T. (2008). The molecular level determination of black carbon in marine dissolved organic matter. Org. Geochem. 39, 396-407. doi: 10.1016/j.orggeochem.2008.01.015

Dittmar, T., de Rezende, C. E., Manecki, M., Niggemann, J., Ovalle, A. R. C., Stubbins, A., et al. (2012a). Continuous flux of dissolved black carbon from a vanished tropical forest biome. Nat. Geosci. 5, 618-622. doi: 10.1038/ngeo1541

Dittmar, T., Koch, B., Hertkorn, N., and Kattner, G. (2008). A simple and efficient method for the solid-phase extraction of dissolved organic matter (SPE-DOM) from seawater. Limnol. Oceanogr. Methods 6, 230-235. doi: 10.4319/lom.2008.6.230

Dittmar, T., Paeng, J., Gihring, T. M., Suryaputra, I., and Huettel, M. (2012b). Discharge of dissolved black carbon from a fire-affected intertidal system. Limnol. Oceanogr. 57, 1171-1181. doi: 10.4319/lo.2012.57.4.1171

Eswaran, H., Van Den Berg, E., and Reich, P. (1993). Organic carbon in soils of the World. Soil Sci. Soc. Am. J. 57, 192-194. doi: 10.2136/sssaj1993.03615995005700010034x

Fasnacht, M. P., and Blough, N. V. (2002). Aqueous photodegradation of polycyclic aromatic hydrocarbons. Environ. Sci. Technol. 36, 4364-4369. doi: $10.1021 /$ es025603k

Field, J. A., de Jong, E., Feijoo Costa, G., and de Bont, J. A. M. (1992). Biodegradation of polycyclic aromatic hydrocarbons by new isolated of whiterot fungi. Appl. Environ. Microbiol. 58, 2219-2226.

Forbes, M. S., Raison, R. J., and Skjemstad, J. O. (2006). Formation, transformation and transport of black carbon (charcoal) in terrestrial and aquatic ecosystems. Sci. Total Environ. 370, 190-206. doi: 10.1016/j.scitotenv.2006.06.007

Glaser, B., Haumaier, L., Guggenberger, G., and Zech, W., (1998). Black carbon in soils: the use of benzenecarboxylic acid as specific markers. Organ. Geochem. 29, 811-819. doi: 10.1016/S0146-6380(98)00194-6

Haemmerli, S. D., Leisola, M. S., Sanglard, D., and Fiechter, A. (1986). Oxidation Of Benzo(A)Pyrene by extracellular ligninases OF phanerochaete-chrysosporium - veratryl alcohol and stability of ligninase. J. Biol. Chem. 261, 6900-6903.

Hammes, K., Schmidt, M. W. I., Smernik, R. J., Currie, L. A., Ball, W. P., Nguyen, T. H., et al. (2007). Comparison of quantification methods to measure fire-derived (black/elemental) carbon in soils and sediments using reference materials from soil, water, sediment and the atmosphere. Global Biogeochem. Cycles 21, 1-18. doi: 10.1029/2006GB002914

Hammes, K., Smernik, R., Skjemstad, J., Herzog, A., Vogt, U., Schmidt, M., et al. (2006). Synthesis and characterisation of laboratory-charred grass straw (Oryza saliva) and chestnut wood (Castanea sativa) as reference materials for black carbon quantification. Org. Geochem. 37, 1629-1633. doi: 10.1016/j.orggeochem.2006.07.003

Hansen, E. H., and Schnitzer, M. (1967). The alkaline permanganate oxidation of Danish illuvial organic matter. Soil Sci. Soc. Am. J. 30, 745-748. doi: 10.2136/sssaj1966.03615995003000060025x

Hedges, J. I., Keil, R. G., and Benner, R. (1997). What happens to terrestrial organic matter in the ocean? Org. Geochem. 27, 195-212. doi: 10.1016/S0146-6380(97)00066-1
Hockaday, W. C., Grannas, A. M., Kim, S., and Hatcher, P. G. (2006) Direct molecular evidence for the degradation and mobility of black carbon in soils from ultrahigh-resolution mass spectral analysis of dissolved organic matter from a fire-impacted forest soil. Org. Geochem. 37, 501-510. doi: 10.1016/j.orggeochem.2005.11.003

Hockaday, W. C., Grannas, A. M., Kim, S., and Hatcher, P. G. (2007). The transformation and mobility of charcoal in a fire-impacted watershed. Geochim. Cosmochim. Acta 71, 3432-3445. doi: 10.1016/j.gca.2007.02.023

Jaffé, R., Ding, Y., Niggemann, J., Vähätalo, A. V., Stubbins, A., Spencer, R. G., et al. (2013). Global charcoal mobilization from soils via dissolution and riverine transport to the oceans. Science 340, 345-347. doi: 10.1126/science.1231476

Johnson, R. L., and Schmidt-Rohr, K. (2014). Quantitative solid-state C-13 NMR with signal enhancement by multiple cross polarization. J. Magn. Reson. 239, 44-49. doi: 10.1016/j.jmr.2013.11.009

Kalbitz, K., Schmerwitz, J., Schwesig, D., and Matzner, E. (2003). Biodegradation of soil-derived dissolved organic matter as related to its properties. Geoderma 113, 273-291. doi: 10.1016/S0016-7061(02)00365-8

Kappenberg, A., Blaesing, M., Lehndorff, E., and Amelung, W. (2016). Black carbon assessment using benzene polycarboxylic acids, limitations for organicrich matrices. Org. Geochem. 94, 47-51. doi: 10.1016/j.orggeochem.2016.01.009

Karich, A., Ullrich, R., Scheibner, K., and Hofrichter, M. (2017). Fungal unspecific peroxygenases oxidize the majority of organic EPA priority pollutants. Front. Microbiol. 8:1463. doi: 10.3389/fmicb.2017.01463

Kim, K. H., Kim, J. Y., Cho, T. S., and Choi, J. W. (2012). Influence of pyrolysis temperature on physicochemical properties of biochar obtained from the fast pyrolysis of pitch pine (Pinus rigida). Bioresour. Technol. 118, 158-162. doi: 10.1016/j.biortech.2012.04.094

Koch, B. P., and Dittmar, T. (2006). From mass to structure: an aromaticity index for high-resolution mass data of natural organic matter. Rapid Commun. Mass Spectrom. 20, 926-932. doi: 10.1002/rcm.2386

Kuhlbusch, T., and Crutzen, P. (1996). "Chapter 16: black carbon, the global carbon cycle, and atmospheric carbon dioxide," in Biomass Burning and Global Change, ed J. Levine (Cambridge, MA: The MIT Press), 160-169.

Li, X. M., Shen, Q., Zhang, D., Mei, X., Ran, W., Xu, Y., et al. (2013). Functional groups determine biochar properties ( $\mathrm{pH}$ and EC) as studied by two-dimensional C-13 NMR correlation spectroscopy. PLoS ONE 8:e65949. doi: 10.1371/journal.pone.0065949

Masiello, C. A. (2004). New directions in black carbon organic geochemistry. Mar Chem. 92, 201-213. doi: 10.1016/j.marchem.2004.06.043

McBeath, A. V., Smernik, R. J., Krull, E. S., and Lehmann, J. (2014). The influence of feedstock and production temperature on biochar carbon chemistry: a solid-state C-13 NMR study. Biomass Bioenergy 60, 121-129. doi: 10.1016/j.biombioe.2013.11.002

McBeath, A. V., Smernik, R. J., Schneider, M. P. W., Schmidt, M. W. I., and Plant, E. L. (2011). Determination of the aromaticity and the degree of aromatic condensation of a thermosequence of wood charcoal using NMR. Org. Geochem. 42, 1194-1202. doi: 10.1016/j.orggeochem.2011. 08.008

Mukherjee, A., and Zimmerman, A. R. (2013). Organic carbon and nutrient release from a range of laboratory-produced biochars and biochar-soil mixtures. Geoderma 193, 122-130. doi: 10.1016/j.geoderma.2012.10.002

Mukherjee, A., Zimmerman, A. R., and Harris, W. (2011). Surface chemistry variations among a series of laboratory-produced biochars. Geoderma 163, 247-255. doi: 10.1016/j.geoderma.2011.04.021

Nakane, M., Ajioka, T., and Yamashita1, Y. (2017). Distribution and sources of dissolved black carbon in surface waters of the Chukchi Sea, Bering Sea, and the North Pacific Ocean. Front. Earth Sci. 5:34. doi: 10.3389/feart.2017.00034

Podgorski, D. C., Hamdan, R., McKenna, A. M., Nyadong, L., Rodgers, R. P., Marshall, A. G., et al. (2012). Characterization of pyrogenic black carbon by desorption atmospheric pressure photoionization fourier transform ion cyclotron resonance mass spectrometry. Anal. Chem. 84, 1281-1287. doi: $10.1021 / \mathrm{ac} 202166 \mathrm{x}$

Reisser, M., Purves, R. S., Schmidt, M. W. I., and Abiven, S. (2016). Pyrogenic Carbon in soils: a literature-based inventory and a global estimation of its content in soil organic carbon and stocks. Front. Earth Sci. 4:80. doi: 10.3389/feart.2016.00080

Roebuck, J. A., Podgorksi, D. C., Wagner, S., and Jaffe, R. (2017). Photodissolution of charcoal and fire-impacted soil as a potential source of dissolved 
black carbon in aquatic environments. Org. Geochem. 112, 16-21. doi: 10.1016/j.orggeochem.2017.06.018

Saeed, T., Ali, L. N., Al-Bloushi, A., Al-Hashash, H., Al-Bahloul, M., Al-Khabbaz, A., et al. (2011). Effect of environmental factors on photodegradation of polycyclic aromatic hydrocarbons (PAHs) in the water-soluble fraction of Kuwait crude oil in seawater. Mar. Environ. Res. 72, 143-150. doi: 10.1016/j.marenvres.2011.07.004

Santin, C., Doerr, S. H., Preston, C. M., and Gonzalez-Rodriguez, G. (2015). Pyrogenic organic matter production from wildfires: a missing sink in the global carbon cycle. Glob. Chang. Biol. 21, 1621-1633. doi: 10.1111/gcb.12800

Schneider, M. P. W., Hilf, M., Vogt, U. F., and Schmidt, M. W. I. (2010). The benzene polycarboxylic acid (BPCA) pattern of wood pyrolyzed between $200^{\circ} \mathrm{C}$ and $1000^{\circ} \mathrm{C}$. Org. Geochem. 41, 1082-1088. doi: 10.1016/j.orggeochem.2010.07.001

Schneider, M. P. W., Pyle, L. A., Clark, K. L., Hockaday, W. C., Masiello, C. A., and Schmidt, M. W. I. (2013). Toward a "molecular thermometer" to estimate the charring temperature of wild land charcoals derived from different biomass sources. Environ. Sci. Technol. 47, 11490-11495. doi: 10.1021/es401430f

Schneider, M. P. W., Smittenberg, R. H., Dittmar, T., and Schmidt, M. W. I. (2009). Analysis of black carbon molecular markers by two chromatographic methods (GC-FID and HPLC-DAD). Geochim. Cosmochim. Acta 73, A1181.

Schneider, M. P. W., Smittenberg, R. H., Dittmar, T., and Schmidt, M. W. I. (2011). Comparison of gas with liquid chromatography for the determination of benzenepolycarboxylic acids as molecular tracers of black carbon. Org. Geochem. 42, 275-282. doi: 10.1016/j.orggeochem.2011.01.003

Spokas, K. A., Cantrell, K. B., Novak, J. M., Archer, D. W., Ippolito, J. A., Collins, H. P., et al. (2012). Biochar: a synthesis of its agronomic impact beyond carbon sequestration. J. Environ. Qual. 41, 973-989. doi: 10.2134/jeq2011.0069

Stevenson, F. J. (1994). Humus Chemistry: Genesis, Composition, Reactions. New York, NY: John Wiley \& Sons.

Stubbins, A., Niggemann, J., and Dittmar, T. (2012). Photo-lability of deep ocean dissolved black carbon. Biogeosciences 9, 1661-1670. doi: 10.5194/bg-9-1661-2012

Wagner, S., Ding, Y., and Jaffé, R. (2017). A new perspective on the apparent solubility of dissolved black carbon. Front. Earth Sci. 5:75. doi: $10.3389 /$ feart.2017.00075

Ward, C. P., Sleighter, R. L., Hatcher, P. G., and Cory, R. M. (2014). Insights into the complete and partial photooxidation of black carbon in surface waters. Environ. Sci. Process. Impacts 16, 721-731. doi: 10.1039/C3EM00597F

Willoughby, A. S., Wozniak, A. S., and Hatcher, P. G. (2016). Detailed sourcespecific molecular composition of ambient aerosol organic matter using ultrahigh resolution mass spectrometry and H-1 NMR. Atmosphere 7, 24. doi: 10.3390/atmos7060079
Wolf, M., Lehndorff, E., Wiesenberg, G. L. B., Stockhausen, M., Schwark, L., and Amelung, W. (2013). Towards reconstruction of past fire regimes from geochemical analysis of charcoal. Org. Geochem. 55, 11-21. doi: 10.1016/j.orggeochem.2012. 11.002

Wozniak, A. S., Shelley, R. U., Sleighter, R. L., Abdulla, H. A.N., Morton, P. L., Landing, W. M., et al. (2013). Relationships among aerosol water soluble organic matter, iron and aluminum in European, North African, and Marine air masses from the 2010 US GEOTRACES cruise. Mar. Chem. 154, 24-33. doi: 10.1016/j.marchem.2013.04.011

Zimmerman, A. (2010). Abiotic and microbial oxidation of laboratoryproduced black carbon (biochar). Environ. Sci. Technol. 44, 1295-1301. doi: 10.1021/es903140c

Zimmerman, A. R., and Gao, B. (2013). "The stability of biochar in the environment," in Biochar and Soil Biota, eds N. Ladygina and F. Rineau (Boca Raton, FL: CRC Press; A Taylor and Francis Group Co.).

Zimmerman, A. R., and Mitra, S. (2017). Trial by fire: on the terminology and methods used in pyrogenic organic carbon research. Front. Earth Sci. 5:95.doi: 10.3389/feart.2017.00095

Ziolkowski, L. A., Chamberlin, A. R., Greaves, J., and Druffel, E. R. M. (2011). Quantification of black carbon in marine systems using the benzene polycarboxylic acid method: a mechanistic and yield study. Limnol. Oceanogr. Methods 9, 140-149. doi: 10.4319/lom.2011. 9.140

Ziolkowski, L. A., and Druffel, E. R. M. (2009). The feasibility of isolation and detection of fullerenes and carbon nanotubes using the benzene polycarboxylic acid method. Mar. Pollut. Bull. 59, 213-218. doi: 10.1016/j.marpolbul.2009.04.018

Ziolkowski, L. A., and Druffel, E. R. M. (2010). Aged black carbon identified in marine dissolved organic carbon. Geophys. Res. Lett. 37. doi: 10.1029/2010GL043963

Conflict of Interest Statement: The authors declare that the research was conducted in the absence of any commercial or financial relationships that could be construed as a potential conflict of interest.

Copyright (C) 2018 Bostick, Zimmerman, Wozniak, Mitra and Hatcher. This is an open-access article distributed under the terms of the Creative Commons Attribution License (CC BY). The use, distribution or reproduction in other forums is permitted, provided the original author(s) and the copyright owner are credited and that the original publication in this journal is cited, in accordance with accepted academic practice. No use, distribution or reproduction is permitted which does not comply with these terms. 